\title{
Information transfer at evening bat colonies
}

\author{
GERALD S. WILKINSON \\ Department of Zoology, University of Maryland, College Park, MD 20742, U.S.A. \\ (Received 21 August 1991; initial acceptance 30 October 1991; \\ final acceptance 16 December 1991; MS. number: A6135)
}

\begin{abstract}
Four lines of evidence indicate that evening bats, Nycticeius humeralis, at nursery colonies in northern Missouri transfer information by following each other to feeding and roosting sites. (1) Daily estimates of insect density from five automated suction traps showed that common prey in evening bat faecal samples, small beetles and flies, occur in rich patches that persist for several days. Bats apparently respond to prey density and variability because these variables independently predict the number of trips and capture success of foraging bats. (2) Videotape records of the time and weight of bats arriving and departing from a colony indicated that adult females leave within $10 \mathrm{~s}$ of each other on second and subsequent foraging trips more often than expected within a night. These records also revealed that bats alternate between apparent following and leading over a summer, that unsuccessful foragers follow previously successful foragers within a night, and that the foraging success of putative followers is greater than that of unsuccessful bats which depart solitarily. (3) Radio-tagged bats often returned to foraging sites both within a night and on successive nights. Furthermore, three of 12 radio-tagged bats flew closer to another radio-tagged bat throughout a night than expected if bats foraged independently. (4) Two field experiments in which bats were excluded from their roosts for one night demonstrated that newly volant bats follow adult females to alternate roosts. The possibility that evening bats acquire information passively by monitoring echolocation signals or actively by vocal advertisement is discussed.
\end{abstract}

Animals that live in groups often suffer higher rates of ectoparasite transmission (Hoogland 1979; Brown \& Brown 1986) and reproductive parasitism (Brown 1984; Brown \& Brown 1988) as well as more competition for food, mates or other critical resources than solitary individuals. Thus, in the absence of habitat limitation, group living must improve an individual's foraging efficiency, risk of predation, or care of young to offset these costs (Alexander 1974). Transfer of information about the location or quality of food patches (Ward \& Zahavi 1973) is one frequently suggested yet rarely demonstrated (Bayer 1982; Weatherhead 1987; Mock et al. 1988; Richner \& Marclay 1991) advantage to forming a communal roost or colony. Although information transfer has been suggested for communally roosting bats (Fleming 1982), only anecdotal data have been reported (Howell 1979; McCracken \& Bradbury 1981; Wilkinson 1985). In this study I investigate whether a temperate insectivorous bat, the evening bat $N y c t i c e i u s$ humeralis, locates resources, such as feeding and roosting sites, by following individuals from a nursery colony.
Most studies purporting to demonstrate information transfer in birds have described coordinated departures from a roost or colony and subsequent arrival at a feeding site, i.e. weaver finches, Quelea quelea (Ward 1965), herons (Krebs 1974; Custer \& Osborn 1978), terns (Erwin 1978; Waltz 1987), hooded crows, Corvus cornix, ravens, $C$. corax (Loman \& Tamm 1980), black vultures, Coragyps atratus (Rabenold 1987), osprey, Pandion haliaetus, (Greene 1987) and cliff swallows, Hirundo pyrrhonota (Brown 1986, 1988a). However, data which show that leaders alternate roles with followers are provided in only one of these studies (Brown 1986). Documenting alternation between leading and following is necessary to discriminate between information parasitism and information exchange (Galef 1991). This distinction is important because whenever more time or energy is required to locate resources independently than that required to wait and follow another forager. following will be more profitable than independent searching. Therefore, when resource patches are difficult to find, following behaviour provides net energetic benefits to participating group members 
either when individuals alternate between leading and following or when direct benefits to group foraging exist, such as improved prey capture (Krebs 1974; Gotmark et al. 1986) or predator detection (Kenward 1978). However, in the absence of group foraging benefits, voluntary reciprocity is unlikely because in a large group cheaters that always follow will be difficult to exclude (Boyd \& Richerson 1988). Furthermore, if all animals follow, no patches will be discovered. Two evolutionary outcomes can be envisioned once following behaviour arises.

An equilibrium proportion of followers may be reached, analogous to the evolution of copying behaviour (Boyd \& Richerson 1985), at which the costs associated with waiting for an independent forager to follow equal those incurred by being followed. Under this scenario leaders do not alternate with followers, so following represents information parasitism. Alternatively, following may be a conditional strategy that favours information exchange only when independent foraging fails. If patch locations are unpredictable in space or time and individuals initially search independently of each other, then any group member could fail initially to locate food. But, as long as successful foragers return to a central place and resource patches are shareable, following will improve average prey intake rates over independent searching. Conditional following might also minimize the risk associated with not finding any food by decreasing the variance in individual intake rates over time (Brown 1988b; Wenzel \& Pickering 1991). Conditional following could be resistant to cheating, i.e. persistent following, if successful independent searching is more profitable than following. Therefore, for information exchange to operate by conditional following, food patches must persist long enough to be visited at least twice but not so long as to favour defence. Food patches must also be far enough away from the central place that they are not easily located (Waltz 1982). Most previous studies of information transfer in the field have used foraging behaviour to infer patch predictability. This approach can be misleding if either capture success or prey density is influenced by the presence of conspecifics. Consequently, independent assessment of the spatial and temporal variation in prey is required to document information transfer.

In light of the preceding discussion, I provide in this paper quantitative data on evening bat prey density, following behaviour, spatial and temporal association among foraging flights, and foraging success, in order to address four questions related to information transfer. Are prey distributed in patches rich enough and persistent enough to make information exchange profitable? Do evening bats follow each other to critical resources? Do evening bats alternate between following and leading other bats to feeding sites? Does following behaviour improve foraging success?

\section{METHODS}

\section{Study Sites and Species}

Observations on $N$. humeralis foraging behaviour were conducted in northern Missouri during June and July 1988 and 1989 , and during a 2 -week period in July 1990. My assistants and I located eight nursery colonies ranging in size from 30 to 130 adult females during this period (Wilkinson, in press). Most of the data used in this study come from two colonies, the Zion colony in a church located $4 \mathrm{~km}$ east of Cainsville, and the Hutton colony in a two-storey farm house $6 \mathrm{~km}$ west of Cainsville. In addition to these two colonies, we conducted exclusion experiments at two other sites: the Busby colony in a farm house $1 \mathrm{~km}$ north of Galt, and the Easton colony in a farm house $2 \mathrm{~km}$ south of New Hampton. Each colony was situated in the attic of an inhabited building on a hill outside a town near several farm ponds, and within $2 \mathrm{~km}$ of a river or stream lined with riparian forest. In this hilly region extensive wooded areas are interspersed with fields in which corn, soy beans or hay are cultivated.

Females arrive at these colonies in April and give birth to two pups during early June. Triplets occur infrequently yielding an average litter size of $2 \cdot 2$ young (Watkins 1970). First flight occurs at 21 days of age (Jones 1967) and weaning takes place about 40 days after parturition (Wilkinson, in press). All bats migrate south to winter hibernation sites; young males leave in late August, while females wait until early October to depart. Females, but not males, return to their natal colonies to rear young in subsequent years (Humphrey \& Cope 1970; Watkins \& Shump 1981). First year female mortality is about $80 \%$ and maximum female longevity is about 5 years (Wilkinson, in press).

Each year on one evening in late May my assistants and I attempted to net all adult females at the 
Zion colony as they departed to forage at dusk. Small numbers of bats werealso captured at the Zion and Hutton colony at other times during each summer in order to attach radio-transmitters. On initial capture each adult female was measured for weight and forearm length and banded with a unique combination of three coloured plastic wing bands. Blood and chest muscle samples were taken from all adult females at the Zion colony and from about 20 females at each of the other colonies (Wilkinson \& Chapman 1991). Biopsy incisions healed within a week, were undetectable in subsequent years and did not alter disappearance rates. In both years over $95 \%$ of all adult females at the Zion colony were banded. Juvenile bats were captured by hand inside the roost (while their mothers were foraging) and uniquely banded with two reflecting bands on one wing and one coloured, numbered band on the opposite wing. At the Zion colony 132 of an estimated 148 pups in 1988 , and 76 of at least 86 pups in 1989, were banded.

\section{Prey Sampling Procedures}

For 60 consecutive days between 1 June and 30 July 1989 we collected insect samples from five remote-controlled, enclosed-cone suction traps (Southwood 1970; Taylor \& Palmer 1972). All five traps were sited within a $1 \cdot 5-\mathrm{km}$ radius of the Zion colony (Fig. 1) and four were within $2 \mathrm{~m}$ of a farm pond or stream. The exception, trap 2, was situated in riparian woods on a bank about $10 \mathrm{~m}$ above a stream. Each trap consisted of a 12-V automobile blower motor which powered a $36-\mathrm{cm}$ four-blade fan in the middle of a $90-\mathrm{cm}$ section of $40-\mathrm{cm}$ diameter air-conditioning duct. Three steel pipe legs riveted to the cylinder acted as a tripod and held the top of the trap $1.5 \mathrm{~m}$ above ground. The top of the trap consisted of a plywood square fitted with a $28-\mathrm{cm}$ diameter plastic funnel whose sides had been replaced with nylon screening. A 50-ml vial filled with $70 \%$ ethanol was affixed to the funnel tip to collect insects. All traps automatically operated for $60 \mathrm{~min}$ each night beginning at 2100 hours when a programmable timer activated a solenoid connected to a deep-cycle battery. Batteries were recharged and replaced at least every 4 days.

With a freshly charged battery the traps produced an air velocity of $7.5 \mathrm{~m} / \mathrm{s}$ at the trap mouth. Because the battery voltage gradually decayed over a 4-day period, the air volume sample was estimated for each of 4 consecutive days after a battery was charged by monitoring the airspeed at the trap mouth during the $60-$ min sampling period. To estimate insect density, I divided the dry biomass of all insects captured in a $60-\mathrm{min}$ period by either 1350 , 1320,1290 or $1080 \mathrm{~m}^{3} / \mathrm{h}$ of air for $0,1,2$, or 3 days since charging, respectively.

We recorded the number of insects with body length less than $5 \mathrm{~mm}, 5-10 \mathrm{~mm}, 10-20 \mathrm{~mm}$, or greater than $20 \mathrm{~mm}$ for each order. The average dry biomass of an insect was estimated by drying a representative sample for each category to constant mass, e.g. 1000 flies less than $5 \mathrm{~mm}$ or 20 beetles greater than $20 \mathrm{~mm}$. Using the average dry biomas of each category, the number of insects of each category captured and the volume of air sampled in an hour, I calculated the overall insect density for each trap on each night.

Minimum and maximum temperature were recorded each day during the summers of 1988 and 1989 at a site $2 \mathrm{~km}$ from the Zion colony. Rainfall records were obtained from a U.S. NOAA weather station about $10 \mathrm{~km}$ from the Zion colony.

\section{Faecal Pellet Analysis}

To verify that the insects collected in suction traps reflected prey density, each day during the 1989 study period we collected all fresh faecal pellets deposited on a $10-\mathrm{cm}^{2}$ ledge beneath roosting bats at the Zion colony. To determine whether the bats changed their feeding habits over the summer we chose 1 day from each of the 8 weeks and dissected four pellets from that day $(N=32$ pellets). Each pellet was placed in a petri dish marked with a $10 \times 10-\mathrm{cm}$ grid, softened and teased apart in $5 \mathrm{ml}$ wetting solution (one part Kodak photo-flo solution to 200 parts water), and spread evenly over the dish. We scored the fraction area of four prey taxa: diptera, coleoptera, lepidoptera, and other, for 10 randomly chosen squares on the grid. Diptera parts were characterized mainly by wing and eye pieces but also by antennae and bristles. Coleoptera parts were identified by elytra pieces, mandibles, tarsi and antennae. Lepidoptera were detected by the presence of scales. The average of the 10 grid squares was used to estimate the proportion of each prey category per pellet.

\section{Following and Foraging Success Observations}

Every night from 1 June to 15 July 1988 and from 1 June to 30 July 1989 I monitored the departure 
and arrival of bats at the Zion colony from 2100 to 0500 hours using a video-camera. In 1988 I illuminated the back of the church with a floodlight and used a video-camera below the apex of the roof to record bats as they flew in or out of the attic access hole. Although we could record departure and arrival times from these tapes, individual band combinations were difficult to distinguish unambiguously because the flying bats produced blurry images. In 1989 I obtained clear pictures by positioning a small halogen light and video-camera with highspeed shutter a few feet above the access hole. In 1989 I also placed a continuously displaying Mettler balance on a platform beneath the access hole with a screen-covered ramp on the taring pan to permit bats that landed on the balance to crawl into the attic. Thus, in 1989 we were able to record arrival and departure times, bat identity, and on about $25 \%$ of arrivals, mass. Departing bats rarely contacted the balance. Mass was recorded when the balance displayed a constant mass within $0.1 \mathrm{~g}$ for at least $0.3 \mathrm{~s}$. Although I tared the scale for the mass of the ramp, moisture and wind often caused the scale to register above zero. To determine bat mass, therefore, I subtracted the median weight displayed on the balance in the absence of any bat during the $10 \mathrm{~s}$ prior to an arrival.

Time of departure and arrival was recorded for all bats on 8 partial nights in 1988, 7 partial nights in 1989 and 11 complete nights in 1989. From these records I calculated the number of trips taken by each bat, the duration of time out of the roost for each bat on each night, and the interval between consecutive departures. I used the latter measure to test for following behaviour. Each night after 2200 hours the number of departures that occurred within a $10 \mathrm{~s}$ interval were counted. I waited until after 2200 hours to avoid the initial synchronous departure that occurs at dusk around 2100 hours. Ten seconds is an estimate of the time it takes a bat to fly $100 \mathrm{~m}$ and out of hearing range of another bat. For comparison, using a heterodyne bat detector (Flan 2.2) we could hear a bat as it flew away from the colony for up to $12 \mathrm{~s}$.

To generate a null distribution for the number of times two independently departing bats would be expected to leave the colony within $10 \mathrm{~s}$ of each other,I used a Monte Carlo simulation which drew an arbitrary departure time from a uniform distribution spanning 0-3600 s for each bat that departed during each hour. By estimating departure intervals hourly this method corrects for uneven foraging activity throughout the night. To obtain the probability associated with the number of putative following events recorded on each night, I compared the total number of departure intervals less than $10 \mathrm{~s}$ that were observed within a night with the distribution generated by 1000 iterations of the simulation.

\section{Radio-tracking Methods}

To determine whether bats returned to foraging sites and foraged independently of each other, we triangulated the position of radio-tagged bats and observed bats foraging using 400000 candlepower spotlights and heterodyne bat detectors (QMC mini). In both 1988 and 1989 we tracked radio-tagged bats over two 4-day periods. For each session we captured four or five bats as they departed at dusk and attached $1 \cdot 2$-g radio transmitters (Wilkinson \& Bradbury 1988) to the fur on the bat's back using Skin-bond colostomy adhesive. Bats were released within $1.5 \mathrm{~h}$ of capture. Beginning with the second night after capture we attempted to obtain synchronous compass bearings every $5 \mathrm{~min}$ on every radio-tagged bat either for the duration of the night at the Hutton colony in 1988 , or for the duration of the first foraging trip at the Zion colony in 1989. To detect the radio signal we used a Custom Electronics receiver connected to a five element Yagi antenna on a 3-6-m aluminium mast. We obtained compass bearings by rotating the mast in the centre of a table on which a compass had been circumscribed. Tracking stations (Fig. 1) were located on hills that were selected after examining bearings taken on the first night of observation. The transmitters had 15-cm whip antennas and operated at $148 \mathrm{MHz}$. This system had a range of over $3 \mathrm{~km}$ in the absence of obstructions. Although I could not measure the error associated with each triangulated coordinate, we did locate bats in alternate roosts on six separate occasions. In each case, the predicted coordinates were within $50 \mathrm{~m}$ of the observed location. Radio transmitters fell off bats 3-6 days after attachment.

Although the radios weighed a little more than the recommended maximum of $10 \%$ of a bat's weight (Wilkinson \& Bradbury 1988), bats carrying radios did not expend significantly more energy per day than those not carrying radios as estimated using doubly-labelled water (S. Steele \& G. S. Wilkinson, unpublished data). Bats with radios also did not differ from bats without radios in the number of foraging trips recorded on videotape 


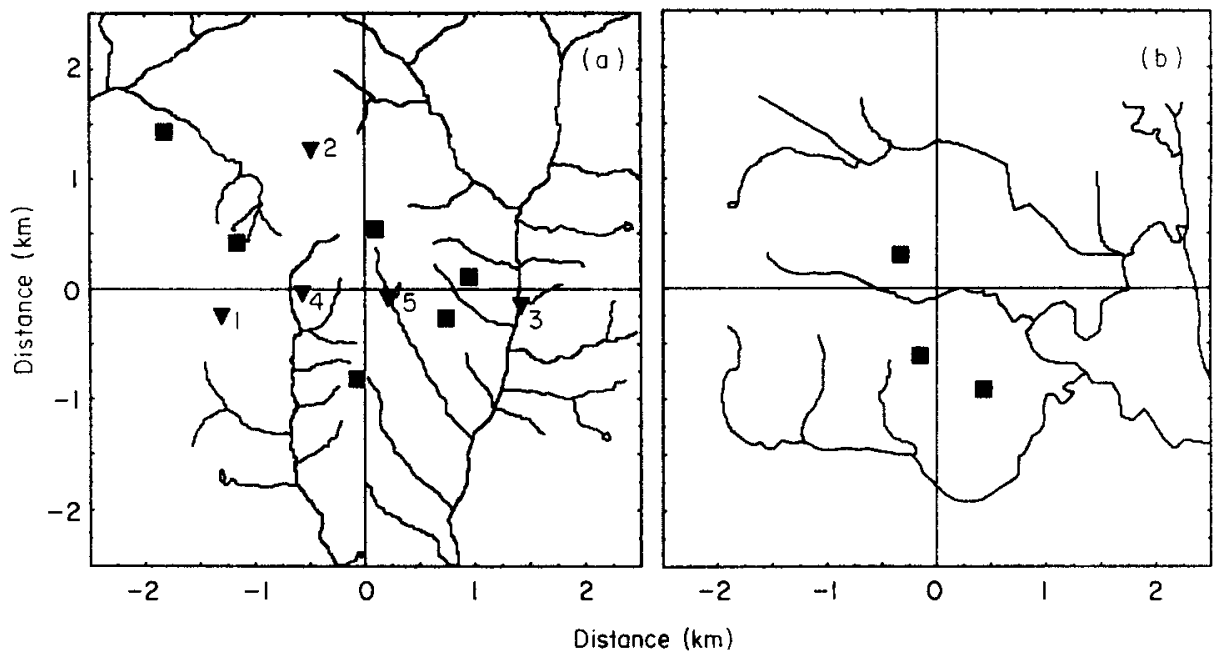

Figure 1. (a) Radio-tracking station ( $(\mathbf{a})$ and insect suction trap ( $\mathbf{V})$ locations around the Zion and (b) Hutton colonies. The colony is situated in the middle of each map and the irregular lines indicate drainages containing water.

each night (unpublished data). However, bats with radios were out of the attic roost for less time $(\bar{X} \pm \mathrm{SE}=141 \pm 13 \mathrm{~min}$ versus $190 \pm 13 \mathrm{~min}$ ) indicating that they either spent less time in alternate roosts or flew a shorter distance than bats without radios (unpublished data). Comparisons of radiotagged bat coordinates may, therefore, provide conservative estimates of distance travelled and spatial or temporal associations among foraging bats.

Spatial and temporal independence of foraging location was estimated using randomization tests. Each test compared the average distance separating two bats throughout a night to a distribution of average distances that would be expected under the assumption of either no spatial dependence or no temporal dependence. For the spatial dependency test on each 5-min interval throughout a night I randomly selected the coordinates of two of the four possible bats. I repeated this process for all 5min intervals in the sample and then computed the average distance between these coordinate pairs. I obtained probability levels by comparing observed average between-bat distances to a ranked distribution containing 1000 randomly generated average distances. To ensure the test used a representative sample, I only report distances from bat dyads with at least 10 simultaneous coordinates per night. Because spatial dependence could be caused by independent attraction to a shared resource, I also tested for temporal dependence by choosing 5-min intervals at random, separately and with replacement, for each of two bats within a night until the number of intervals sampled equalled the number of intervals for which those two bats had compass bearings. Probability levels were obtained directly by comparing observed distances to the ranked distribution of 1000 randomly generated distances for each pair of bats.

\section{Roost Exclusion Experiment}

Because evening bats late in lactation often visit hollows in trees at night and sometimes use them as day roosts, I postulated that newly volant bats would locate alternate roosts by following other bats. Many tree roosts are in small cavities, such as old woodpecker nests (personal observation). Consequently, many possible alternate roosts were available in the woods around each colony. Therefore, to verify that bats follow each other, I performed two roost exclusion experiments in midJuly, 1990. The young of the year had been flying for no more than 2 weeks at this time. Bats of this age rarely spend more than $1 \mathrm{~h}$ out of the roost each night and should not, therefore, have had much opportunity to locate tree roosts on their own. Thus, the presence of juveniles with adult bats in alternate roosts provides direct evidence for following behaviour.

On 13 July we counted the number of departing bats at the Busby colony and captured six adult females on each of which I attached radiotransmitters. On 14 July we monitored the time 


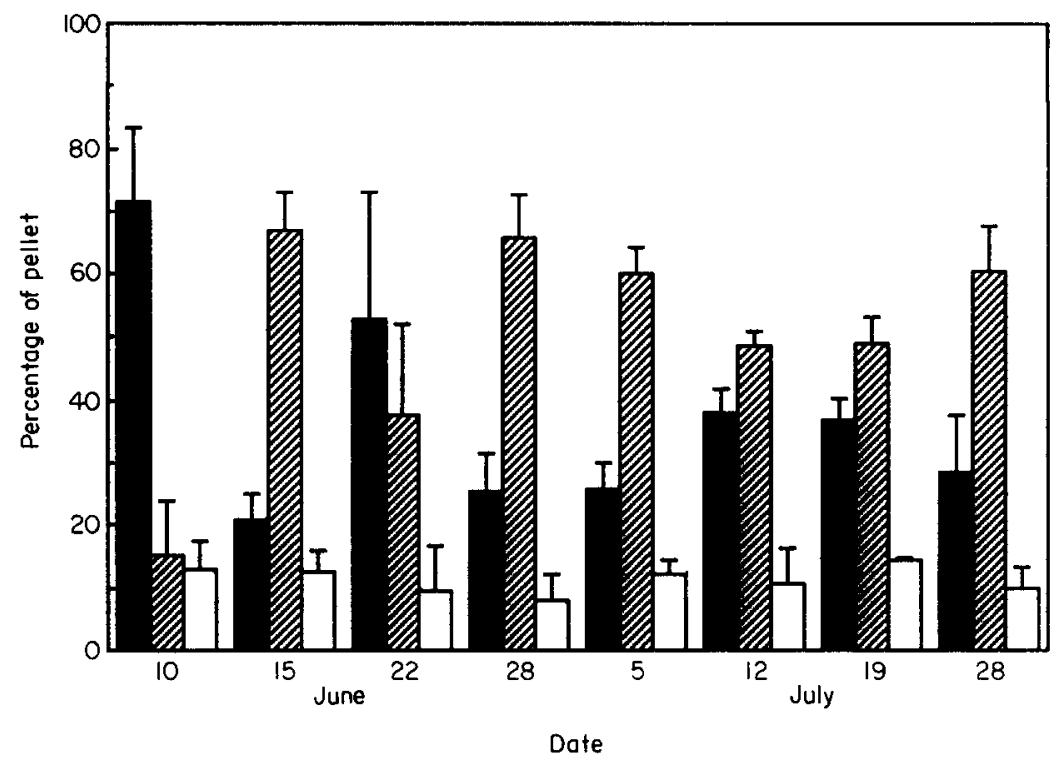

Figure 2. Mean (+SE) percentage of faecal-pellet volume consisting of diptera ( $\square$ ), coleoptera ( $\square$ ), or lepidoptera ( $\square$ ) parts from 32 faecal pellets taken from the Zion colony over an 8-week period in 1989.

and direction of departures of all radio-tagged bats and at 2300 hours, closed the access hole to the attic roost. Bat activity at the roost access hole was recorded from 2300 to 2400 hours with a videocamera. On 15 July we unblocked the attic roost and then searched for the transmitters by driving along all roads within a $3 \mathrm{~km}$ radius of the colony. Bats were counted and some captured as they departed that night from an alternate roost. This experiment was replicated at the Easton colony on 16-18 July exactly as decribed for the Busby colony except that I attached transmitters to eight, rather than six adult bats and visually observed the activity at the roost after excluding the bats, rather than videotaping it.

\section{RESULTS}

\section{Diet}

On average, the $N$. humeralis pellets contained $38 \%$ fly parts, $50 \%$ beetle parts, and $10 \%$ moth scales (Fig. 2). The remaining $2 \%$ consisted of caddisflies and other unidentifiable prey. On the basis of beetle mandible size, and eye part size of flies, we estimated that most of the prey captured by bats were in the 5-10 mm size range of insects caught in the suction trap. ANOVAs on the arcsine-squareroot transforms of beetle and moth proportions indicated that there was significant variation between weeks in 1989 in the proportion of beetles taken $(F=4 \cdot 18, P=0.004)$ but not in the proportion of moths captured $(F=1.07, P=0.41)$. Because the proportion of each pellet composed of beetle parts correlated highly with the proportion of fly parts $(r=-0.94, P<0.001, N=32)$, there was similar variation between weeks in the proportion of flies in the bats' diet. Fisher's protected leastsignificant-difference post-hoc test indicated significant differences in beetle proportions between weeks 1 and 2, and weeks 2 and 3 , flies being the most abundant prey type in weeks 1 and 3 (Fig. 2).

\section{Prey Density and Variability}

The suction traps proved effective at capturing small flying insects: over 500 insects were routinely captured in a $60 \mathrm{~min}$ sampling period. For a variety of reasons, such as rainfall filling collection tubes or corrosion of solenoid contacts, some traps failed to operate each night. Nevertheless, a total of 195 samples $(\bar{X} \pm \mathrm{SE}=3.48 \pm 0.30$ samples per night $)$ were collected on 57 days and contained over 67000 insects. Large fast-flying, heavy-bodied insects were rarely captured (e.g. only one sphingid) and probably evaded the traps. The traps did, however, sample several of the prey identified in faecal pellets. For example, a chironomid midge with uniquely shaped compound eyes was common in 


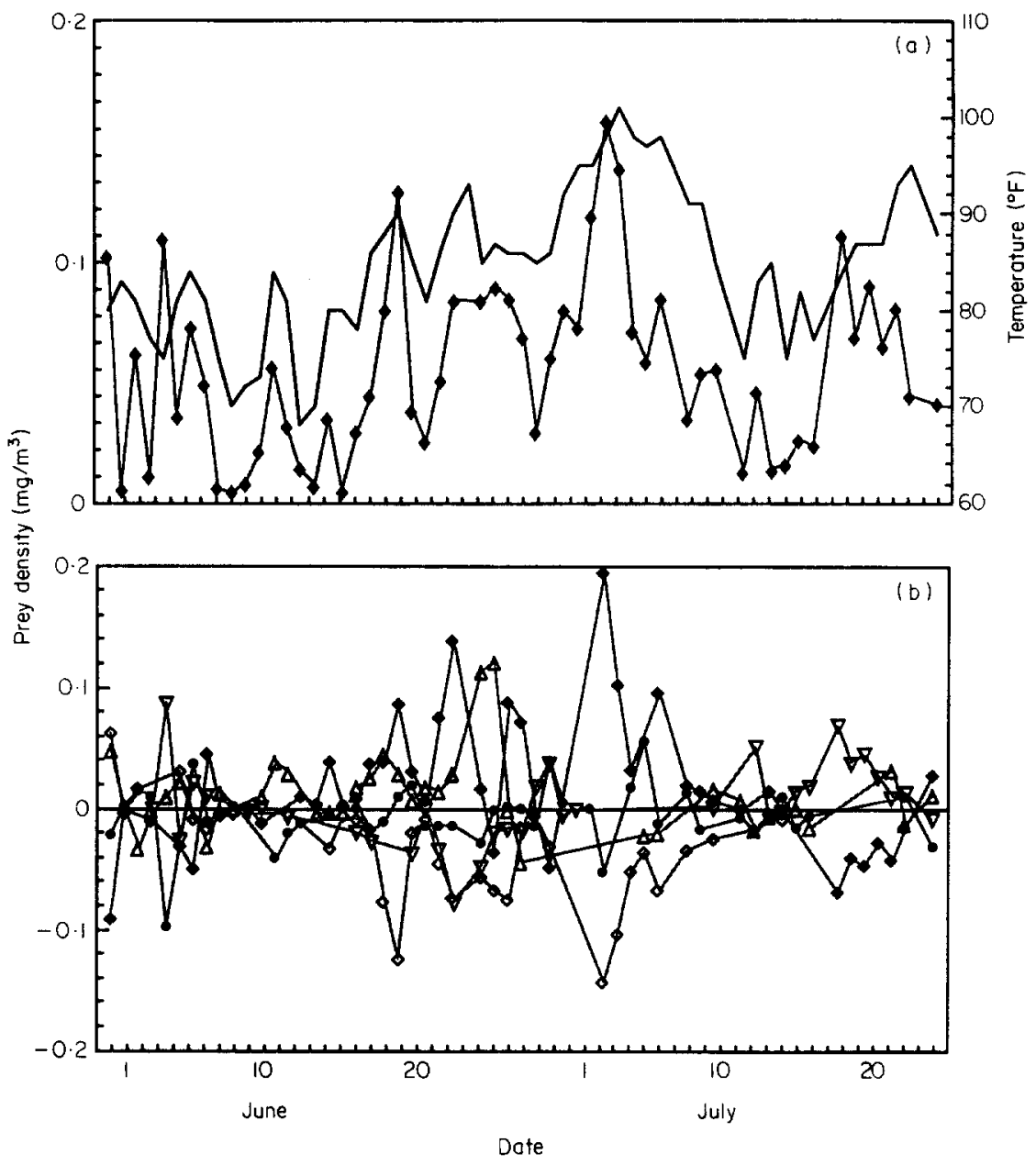

Figure 3. (a) Prey density averaged over all five insect suction traps $(\bullet)$ and maximum temperature $(-)$ for each day in 1989. (b) Deviation from the mean prey density for each of the five suction traps: $\operatorname{trap} 1(\diamond), \operatorname{trap} 2(\diamond), \operatorname{trap} 3(\bullet)$, $\operatorname{trap} 4(\Delta)$, trap $5(\nabla)$, for those days each trap operated.

several bat pellets and on some nights in samples from traps near streams.

Because the faecal pellet analyses indicated that evening bats fed primarily on flies and beetle, I included only dipteran, coleopteran, trichopteran, ephemeropteran, and neuropteran insects less than $20 \mathrm{~mm}$ in length when estimating prey density. Average prey density increased until June, peaked during the first week of July and mirrored maximum temperature (Fig. 3a). Multiple regression analyses indicated that maximum temperature $(l=$ $5.57, P<0.0001)$, but not minimum temperature $(t=0.81, P=0.42)$, on each night significantly predicted average prey density $\left(R^{2}=0.45, N=56\right.$, $P<0.001)$.
Variation among traps in nightly capture success resulted in prey density differences between two traps that often exceeded mean prey density (Fig. 3). This variability was not caused by one trap having consistently higher densities than other traps. In contrast, each of the five trap sites had the highest prey density on at least 3 nights, and four of the traps had the maximum density on 9 or more nights (Fig. 3b). Some sites did, however, have the highest densities on several consecutive nights. For example, trap 1 (Fig. 1) had the highest density over 3 consecutive days on two occasions and trap 5 had the highest density over 6 consecutive days. These periods of high prey density at a single site were usually due to the mass emergence of midges, 


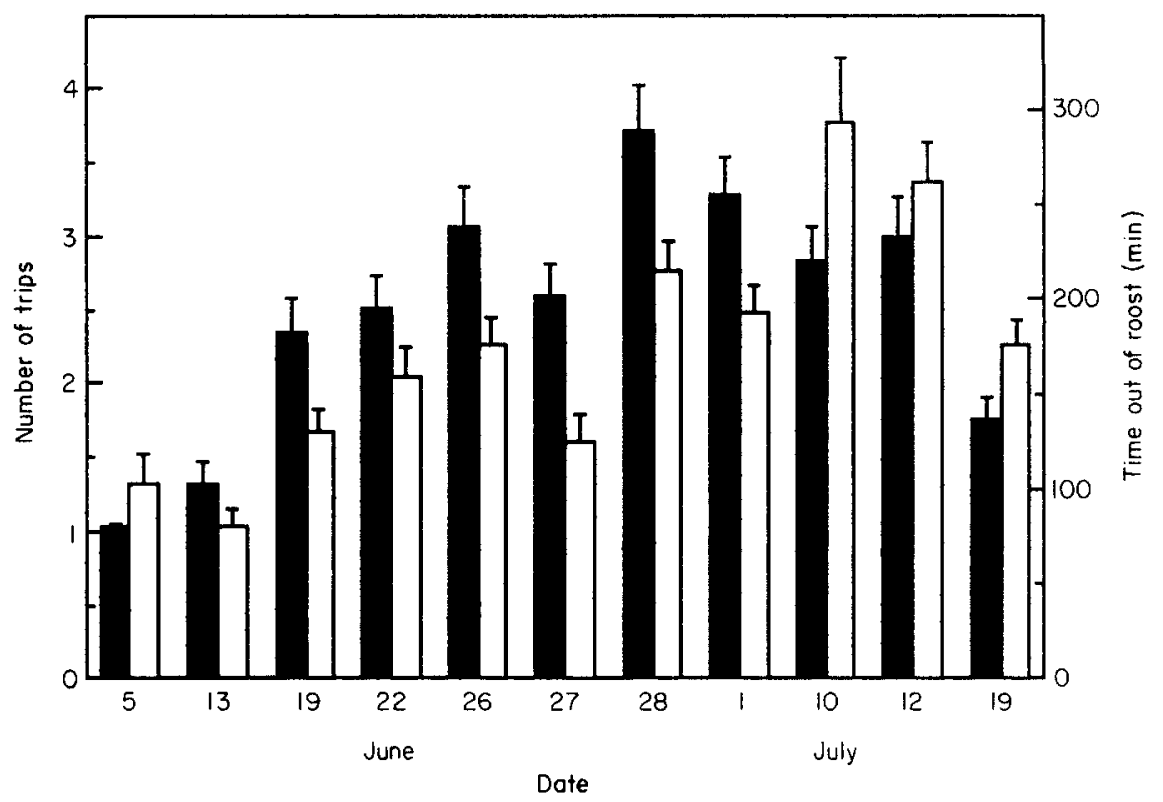

Figure 4. Mean (+SE) number of foraging trips ( $\square$ ) and total time spent out of the roost $(\square)$ for all banded bats observed departing from Zion colony on an 8-h videotape each night.

mayflies, or caddisflies over a period of 1-3 days. Visits at dusk to farm ponds without suction traps indicated that mass emergences were not synchronized among ponds. Thus, even though prey density peaked in early July when young evening bats were beginning to feed themselves, no one site provided a continuous source of prey. Rich potential foraging sites occurred throughout the foraging area and often lasted for more than 1 day.

\section{Effects of Prey Density on Foraging Behaviour}

If the temporal and spatial variability observed among the insect suction traps accurately reflects temporal variation in evening bat prey patch size, then either the frequency of foraging trips, the amount of foraging time, or the amount of prey captured should be influenced by estimated prey density and variability. Foraging behaviour may also be influenced by daily milk production because at peak lactation, which occurs 15 days after parturition, evening bats produce half of their body mass per day in milk (Steel 1991). Therefore, to validate the prey-sampling method we conducted three multiple regression analyses using average prey density, the coefficient of variation in prey density among the five traps, and the amount of milk produced for the litter on that day as inde- pendent variables to predict either the number of foraging trips, the average time out of the roost on a foraging trip, or the total weight of a returning bat obtained from the video records. Milk production was estimated using a cubic polynomial fit to water intake of known-aged pups (Steele 1991). Minimum temperature and the amount of rainfall recorded for that day were included in all regressions because of their potential effects on foraging activity. Maximum temperature was not included to avoid multi-collinearity problems caused by the high correlation between maximum temperature and average prey density noted above.

The number of foraging trips a bat took on a night was strongly influenced by its stage of reproduction. In 1989 the bats at the Zion colony gave birth between 14 and 21 June. Videotapes scored before that period show that most pregnant bats made only a single foraging trip (Fig. 4). In contrast, at peak lactation in late June and early July most bats took three or more trips per night. The number of foraging trips then declined as bats spent longer periods away from the colony. The multiple regression analysis corroborates these observations through a highly significant effect of estimated milk production but also reveals a strong positive relationship between estimated prey density and number of foraging trips (Table I). In combination 
Table I. Multiple regression coefficients and associated significance levels for five possible determinants of the number of foraging trips per night. the average duration of a foraging trip, and the mass of a bat after returning from a foraging trip

\begin{tabular}{|c|c|c|c|c|c|c|}
\hline \multirow[b]{2}{*}{ Variable } & \multicolumn{2}{|c|}{ Number of trips } & \multicolumn{2}{|c|}{ Foraging time } & \multicolumn{2}{|c|}{ Bat mass } \\
\hline & Coefficient & $P$ & Coefficient & $P$ & Coefficient & $P$ \\
\hline Intercept & 0.78 & & -393.62 & & $15 \cdot 17$ & \\
\hline Milk production & 0.47 & $<0.001$ & $6 \cdot 10$ & $0 \cdot 183$ & 0.11 & 0.536 \\
\hline Prey density & 14.09 & $<0.001$ & 672.80 & 0.056 & -28.02 & $<0.001$ \\
\hline Prey variability & -0.01 & 0.035 & -0.07 & 0.893 & 0.03 & 0.039 \\
\hline Rainfall & -1.04 & 0.017 & $-135 \cdot 57$ & $<0.001$ & $-1 \cdot 16$ & 0.041 \\
\hline Minimum temperature & 0.02 & $0 \cdot 260$ & $9 \cdot 15$ & $<0.001$ & $-1 \cdot 16$ & 0.051 \\
\hline
\end{tabular}

the five independent variables explained $46 \%$ of the variation in number of foraging trips $(F=44.72$, $N=264, P<0 \cdot 0001)$. Prey variability and rainfall showed weaker, although still significant, negative relationships while minimum temperature exhibited no relationship. In contrast to these results, only two of the five independent variables, minimum temperature and rainfall, proved to be significant predictors of the average time spent out of the roost each night (Table I). The five independent variables explained $34 \%$ of the variation $(F=22 \cdot 2, N=219$, $P<0.0001)$. Rainfall exhibited a strongly negative relationship while minimum temperature showed a strong positive relationship with the amount of time spent out of the roost.

Considerable variation in foraging success also existed within and between nights. On several occasions returning bats registered $4 \mathrm{~g}$ more than their estimated unfed weights while some bats returned weighing 1 g or more below their estimated unfed weights. Unfed bat weights were estimated from a regression of mass on forearm length taken from bats captured in mist-nets as they departed at dusk. Over all nights, $20 \cdot 2 \%(N=238)$ of lactating adult female bats returned to the roost weighing less than their estimated unfed weight. Even though the multiple regression analysis of the mass of returning bats on the five independent variables explained only $17 \%$ of the variation $(F=7 \cdot 49, N=$ 191, $P=0.0001$ ), prey density exhibited a strong negative relationship with mass of returning bats (Table I). Prey variability showed a positive relationship and both minimum temperature and rainfall exhibited negative relationships (Table I).

To determine whether and how evening bats foraged at sites with traps, we conducted $13 \mathrm{~h}$ of observations with bat detectors and spotlights at ponds or streams on 8 evenings between 29 June and 27
July 1989. We observed banded $N$. humeralis, including one bat with a radio, on 16 separate occasions. Eleven of these sightings consisted of a lone bat, once two bats (one banded and one unbanded) flew together over a pond, and once one banded bat was joined by two other bats as it hunted along riparian forest edge near a pond. On four occasions a banded bat flew down to the pond to drink or feed near the surface. On two separate occasions a bat was continuously observed feeding over a $10-$ min period. In both cases these bats flew in forest clearings along edges of vegetation at between 3 and $10 \mathrm{~m}$ and periodically dove, sometimes nearly to the vegetation or ground, when emitting a feeding buzz. Thus, evening bats sometimes captured insects sampled by our traps.

\section{Following Behaviour}

On numerous nights in both 1988 and 1989 more bats departed within $10 \mathrm{~s}$ of each other than would be expected by chance given the number of bats that departed from the Zion colony after 2200 hours on that day (Fig. 5). The average ( $\pm \mathrm{SE}$ ) interval between bats that departed within 10 s of each other was $4 \cdot 3 \pm 2 \cdot 7 \mathrm{~s}$. The modal number of bats departing together was two although as many as five bats were seen leaving within a 10-s interval. Proportionately more bats left within $10 \mathrm{~s}$ of each other during 1988 than $1989\left(\chi^{2}=27 \cdot 8, d f=1\right.$, $P<0.001$ ), i.e. 20.0 versus $9.2 \%$ of all departures, respectively. More adult females were present at the Zion colony in 1988 than 1989 , about 80 as compared to 40 .

Individuals departed both before and after other bats more often than expected if there were separate leaders and followers in the colony. Of 25 bats that were observed departing either before (led) or after 


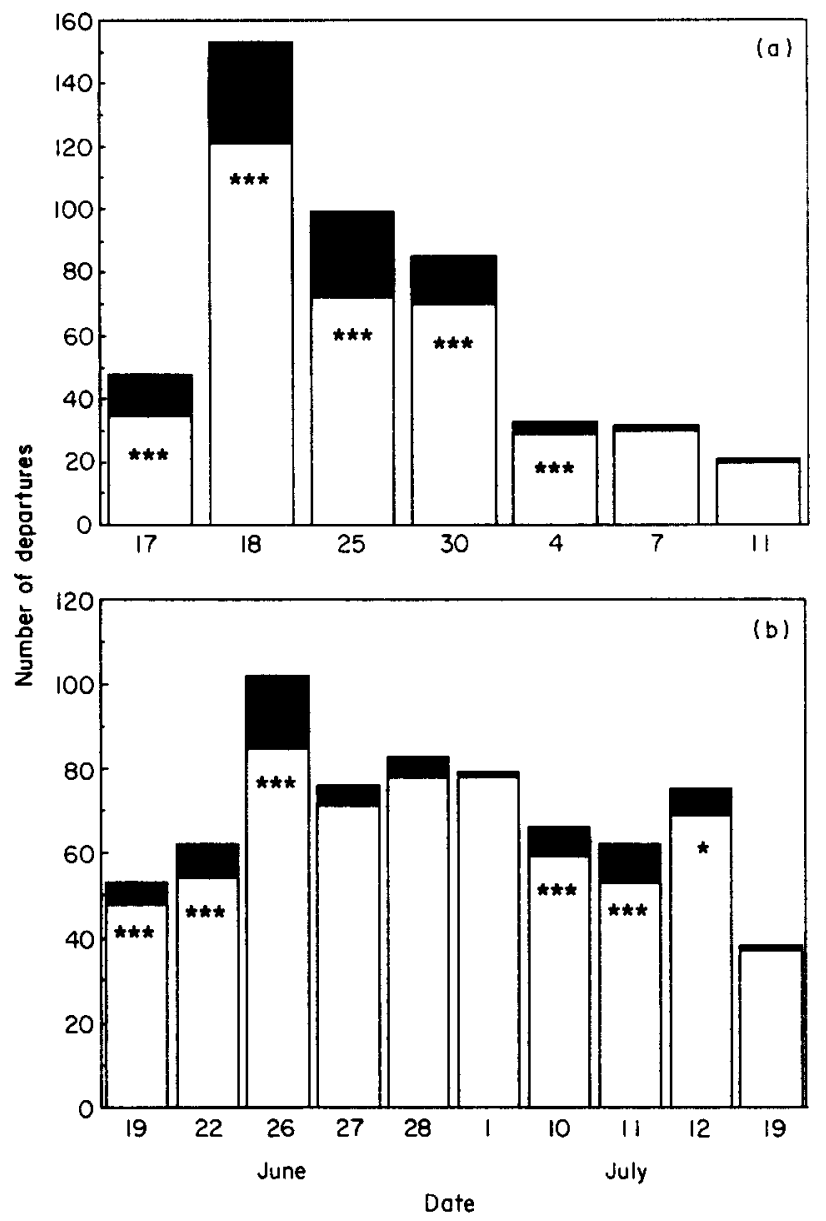

Figure 5. Number of departures less than ( $\square$ ) and greater than $(\square) 10$ s apart recorded after 2200 hours on (a) 7 nights in 1988 and (b) 11 nights in 1989. Asterisks indicate the probability of observing an equivalent number of $10-s$, or less, departure intervals by chance assuming that departures occur at random with respect to time. ${ }^{*} P<0.05 ;{ }^{* * P}<0.01$; ${ }^{* * *} P<0.001$.

(followed) another bat more than once in 1989, $76 \%$ both led and followed $\left(\chi^{2}=27 \cdot 5, d f=1\right.$, $P<0.0001$ ). Furthermore, $89 \%$ of the 19 bats that led or followed more than twice, both led and followed $\left(\chi^{2}=27 \cdot 3, d f=1, P<0.0001\right)$. Of the 63 cases of presumptive following behaviour, 30 of the 38 banded adult females acted as leaders and 27 acted as followers. In two cases, the follower and leader exchanged roles. No bats ever followed the same leader on two different nights. Between 10 and 19 July young of the year followed an adult bat on four occasions and led an adult bat on three occasions. Thus, following alternates with leading, over time, and leading is not restricted to a subset of the colony such as older, more experienced females.
If following resulted in locating food patches more reliably, then bats should have weighed more after following a previously successful bat than after departing alone. As predicted, lactating adult female bats that followed other adult females weighed more upon return after following $(\bar{X} \pm \mathrm{SE}=13.0 \pm 0.7)$ than after their previous trip $(10.8 \pm 0.6 \mathrm{~g}$, Student's $t=2 \cdot 35, d f=16, P=0.016)$. The bats that were followed weighed more $(12.5 \pm 0.5 \mathrm{~g})$ after their first trip than the follower bats (Student's $t=2 \cdot 30, d f=21, P=0.016$ ). For comparison, bats that gained less than $1 \mathrm{~g}$ on a foraging trip and did not subsequently follow another bat $(9 \cdot 9 \pm 0.2 \mathrm{~g})$ did not increase weight significantly after their next foraging trip $(10.6 \pm 0.3 \mathrm{~g}$, 
Table II. Average observed distance $(\mathrm{km})$ and threshold expected distance from a randomization procedure (see text) for detecting a significant spatial or temporal association between pairs of radio-tagged bats at the Hutton colony on two nights in 1988

\begin{tabular}{lccccc}
\hline Date & Bat pair & $N+$ & $\begin{array}{c}\text { Average } \\
\text { distance }\end{array}$ & $\begin{array}{c}\text { Spatial } \\
\text { association } \\
\text { distance }\end{array}$ & $\begin{array}{c}\text { Temporal } \\
\text { association } \\
\text { distance }\end{array}$ \\
\hline 19 June & $490-491$ & 76 & 0.122 & $0.275^{* *}$ & 0.097 \\
& $490-510$ & 73 & 0.489 & 0.275 & 0.341 \\
& $490-547$ & 73 & 0.250 & $0.275^{*}$ & $0 \cdot 146$ \\
& $491-510$ & 80 & 0.441 & 0.275 & 0.351 \\
& $491-547$ & 81 & 0.259 & $0.275^{*}$ & 0.158 \\
& $510-547$ & 83 & 0.586 & 0.275 & 0.430 \\
& $490-491$ & 65 & 0.678 & 0.418 & 0.505 \\
& $490-510$ & 72 & 0.626 & 0.418 & 0.588 \\
& $490-547$ & 63 & 0.524 & 0.418 & $0.558^{*}$ \\
& $491-510$ & 65 & 0.377 & $0.418^{*}$ & 0.349 \\
& $491-547$ & 56 & 0.343 & $0.418^{*}$ & 0.302 \\
& $510-547$ & 61 & 0.531 & 0.418 & 0.406 \\
\hline
\end{tabular}

$\dagger$ Number of simultaneous (i.e. within $5 \mathrm{~min}$ ) $X, Y$ coordinates recorded for each bat pair.

${ }^{* *} P<0.05 ;{ }^{* *} P<0.001$.

paired $t=1 \cdot 63, P=0 \cdot 12, d f=17$ ). Thus, foraging success improved when unsuccessful bats followed previously successful foragers.

\section{Spatial and Temporal Associations among Foraging Bats}

For information transfer to occur, successful foragers must return to above average foraging sites. Because rich prey patches apparently persist for several days, bats could be recruited in the same night or on successive nights. Such recruitment should cause temporal associations among bats that forage together and spatial associations among bats that continue to exploit the same resource patches. Three of the four radio-tracking episodes provided enough data to test for spatial and temporal independence. In 1988 I succeeded in tracking four bats from dusk until dawn on 19 and 20 June and three bats on 21 June. These four bats were radio-tracked when their pups were between 11 and 20 days of age, i.e. during peak lactation, and made up to five foraging trips each night. On both 19 and 20 June two or more pairs of bats foraged in the same area, as indicated by significant spatial associations, but not at the same time (Table II). On 20 June, one pair of bats showed a temporal association even though they did not exhibit a spatial association. Examination of the data reveals that these two bats exhibited coordinated departures and arrivals and flew to similar locations on their first two trips (Fig. 6). However, because these two bats foraged in different locations on their fourth trip, the average distance separating the bats was not low enough to indicate a spatial association. Taken together, these radio-tracking data show that some bats return to the same foraging site on multiple occasions while others may visit three or more sites within a night (Fig. 6).

To determine whether bats might also recruit to patches on successive nights I tested for spatial and temporal independence between four bats on one night in June and four bats on three consecutive nights in July 1989 at the Zion colony. Seven of these bats gave birth to two pups between 16 and 18 June while bat 432 gave birth on 23 June. Thus, the June session occurred just before peak lactation, whereas in mid-July the pups were 4 weeks of age or older and had been flying for a week. Because tracking was terminated after all bats had returned from their initial foraging trip, usually by 2300 hours, fewer simultaneous compass bearings were taken from each pair of bats than were recorded in 1988, resulting in greater average distances between bats in 1989 (Table III) than in 1988 (Table II). As at the Hutton colony, at least one pair of bats foraged in the same area each night as indicated by a significant spatial association (Table III). Furthermore, a 


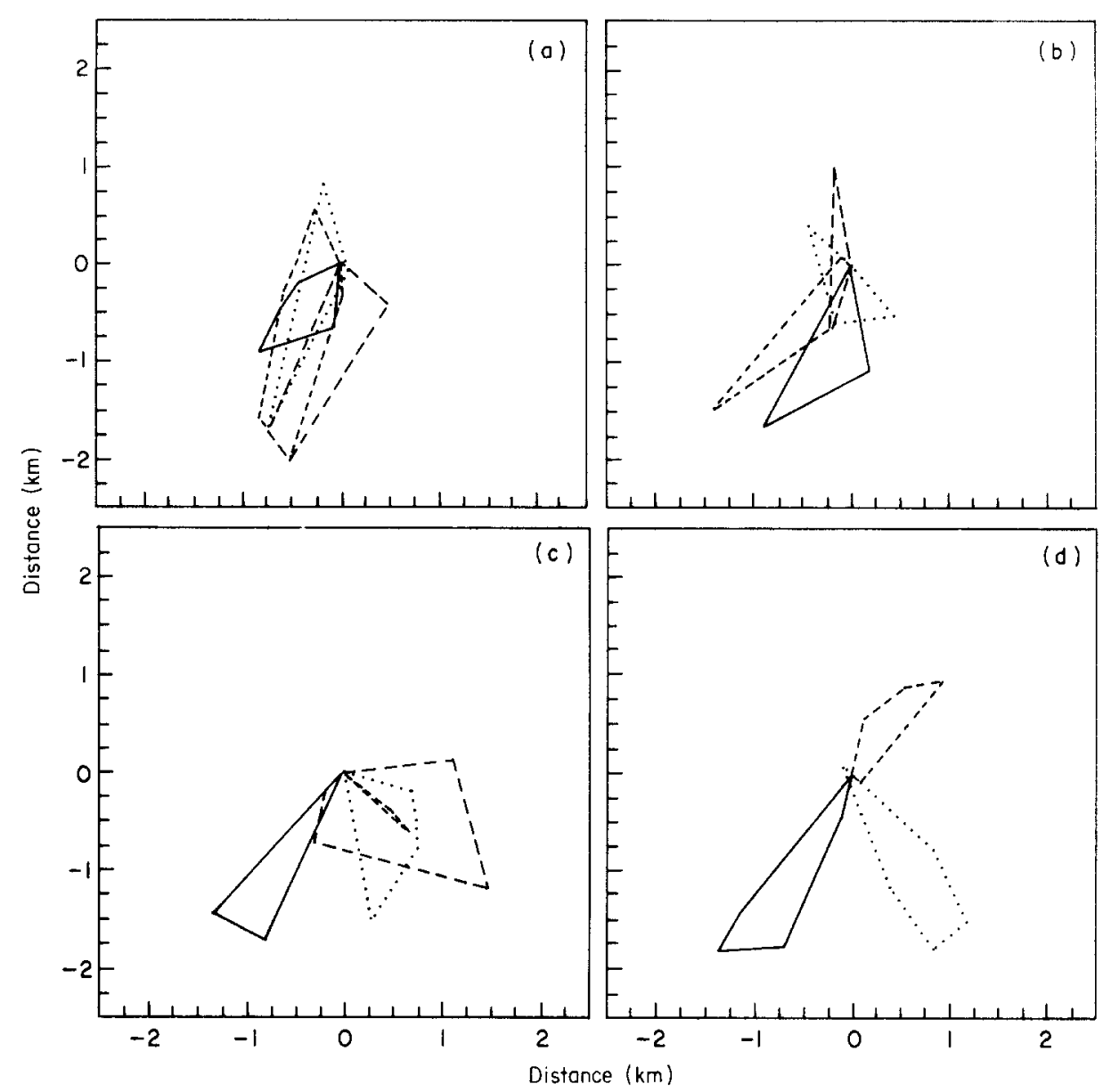

Figure 6. Minimum convex polygons for each of four radio-tagged bats tracked at the Hutton colony on successive trips: (a) first, (b) second, (c) third and (d) fourth trips taken on one night, 20 June 1988. Bat band numbers were 490 ( - ), $491(---), 510(--)$ and $547(\cdots)$. Orientation and scale of map is the same as Fig. $1 \mathrm{~b}$.

pair of bats on 17 July and a different pair on 19 July showed both spatial and temporal associations (Table III). Thus, some bats also returned to the same sites on successive days (Fig. 7) and appeared to travel together. Inspection of the foraging ranges of these eight bats (Fig. 7) also showed that bats foraged in all directions from the colony and usually travelled more than $1 \mathrm{~km}$ to feed near streams or ponds (cf. Fig. 1). The polygons for bats 417 and 889 in Fig. $7 b$ do not overlap the origin because both bats returned to a hollow tree roost away from the attic.

\section{Roost Exclusion Experiment}

Both exclusion experiments indicated that young bats followed adult bats and that at least $40 \%$ of the bats in each colony moved to a single roost site. The day after exclusion five of six radio-tagged Busby bats were located in a hollow tree $0.7 \mathrm{~km}$ east of the home roost and seven of eight radio-tagged Easton bats were discovered in a hollow tree $1.6 \mathrm{~km}$ north of the home roost. The second tree roost was located in the middle of about $1.0 \mathrm{~km}^{2}$ of woods. On the night after exclusion at least 35 (including 10 captured juveniles) of the 85 bats from the Busby colony and at least 130 (including 47 captured juveniles) of 320 bats from the Easton colony left the trees. These counts underestimate the number of bats present because both trees had multiple exit holes, which made counting difficult, and because I only observed departures until darkness. One week after each exclusion I detected no bats in either tree 
Tabie III. Average observed distance $(\mathrm{km})$ and threshold expected distance from a randomization procedure (see text) for detecting a significant spatial or temporal association between pairs of radio-tagged bats on their first foraging trips at the Zion colony on 4 nights in 1989

\begin{tabular}{clllll}
\hline Date & Bat pair $\dagger$ & $N \ddagger$ & $\begin{array}{c}\text { Average } \\
\text { distance }\end{array}$ & $\begin{array}{c}\text { Spatial } \\
\text { association } \\
\text { distance }\end{array}$ & $\begin{array}{c}\text { Temporal } \\
\text { association } \\
\text { distance }\end{array}$ \\
\hline 28 June & $409-419$ & 18 & 0.818 & 0.465 & 0.409 \\
& $409-432$ & 11 & 0.802 & 0.465 & 0.366 \\
& $409-717$ & 15 & 1.309 & 0.465 & 0.505 \\
& $419-432$ & 29 & 0.394 & $0.465^{*}$ & 0.205 \\
& $419-717$ & 28 & 0.498 & 0.465 & 0.357 \\
17 July & $432-717$ & 18 & 0.860 & 0.465 & 0.345 \\
& $417-889$ & 20 & 0.379 & $0.787^{* *}$ & $0.380^{*}$ \\
& $417-1187$ & 19 & 1.328 & 0.787 & 0.954 \\
18 July & $889-1187$ & 13 & 1.615 & 0.787 & 0.942 \\
& $289-417$ & 24 & 1.246 & 0.914 & 1.077 \\
19 July & $289-1187$ & 19 & 1.770 & 0.914 & 1.578 \\
& $417-1187$ & 21 & 0.720 & $0.914^{*}$ & 0.512 \\
& $289-889$ & 19 & 0.335 & $0.681^{* *}$ & $0.379^{*}$ \\
& $289-1187$ & 17 & 1.694 & 0.681 & 1.578 \\
& $889-1187$ & 11 & 1.011 & 0.681 & 0.554 \\
\hline
\end{tabular}

tOnly pairs with $\geqslant 10$ simultaneous coordinates are included.

$\ddagger$ Number of simultaneous (i.e. within $5 \mathrm{~min}$ ) $X, Y$ coordinates recorded for each bat pair.

${ }^{* *} P<0 \cdot 05 ; * * P<0.001$.

indicating that these sites were probably not used as nursery colonies prior to the exclusions.

Radio-tracking data collected on the night of the exclusion indicated that most of the radio-tagged bats neither left together nor foraged near the alternate roost site. At the Busby colony the average $( \pm \mathrm{SE}$ ) interval between departing radio-tagged bats was $9.2 \pm 2.6 \mathrm{~min}$. Four of the six bats, including two bats that left together, flew east from the colony on a bearing of $75^{\circ}$ while two others initially headed on a bearing of $110^{\circ}$. Both directions led towards a river $2 \mathrm{~km}$ east of the colony. All bats except one flew out of radio-tracking range while foraging. The bat within range appeared to forage near the hollow tree that was eventually used as the alternate roost. At the Easton colony four radio-tagged bats spent the night after capture and before exclusion in an unknown alternate roost. These four bats initially foraged at least $1 \mathrm{~km}$ southwest of the colony. Two of the four bats that left the Easton house independently flew due south of the colony to feed. One of the other bats flew northeast at $50^{\circ}$ and the eighth bat flew northwest at $340^{\circ}$ in the direction of the alternate roost.
Observations at the Easton colony and the videotape made at the Busby colony indicate that when bats returned to enter the attic they often landed at the blocked opening while giving conspicuous, audible broad-band vocalizations. At the Easton colony we observed many bats wheeling in front of the colony while giving these calls. Although the video camera field of view was only large enough to see bats as they landed at the blocked opening, many vocalizations could be heard on the tape and were followed by periods of silence as if a group of bats had flown off together.

\section{DISCUSSION}

\section{Following Behaviour}

The data presented in this paper address three hierarchically related questions regarding information transfer, the first being: does information transfer occur in this species, i.e. do evening bats follow each other to resource patches? The roost exclusion experiment demonstrates that at least juvenile and possibly some adult bats follow adult 


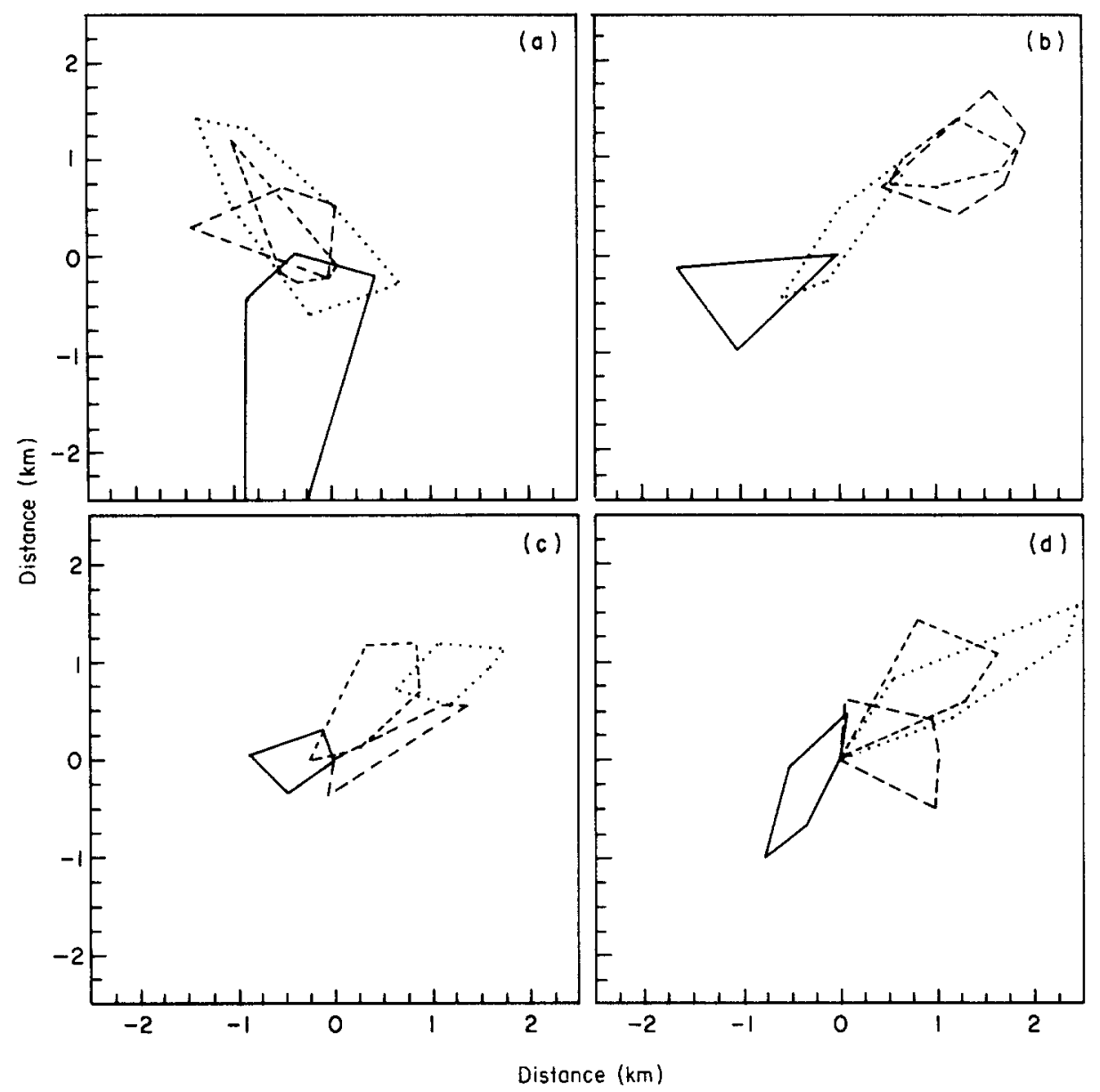

Figure 7. Minimum convex polygons for each of four radio-tagged bats tracked on their first foraging trip at the Zion colony on 4 days in 1989: (a) $28 \mathrm{June}$, (b) $17 \mathrm{July}$, (c) $18 \mathrm{July}$ and (d) $19 \mathrm{July}$. Bat band numbers in (a) are 409 ( - ), 419 $(--), 432(--), 717(\cdots)$ and in (b), (c) and (d) are $2890(-), 417(--), 889(-\cdots)$ and $1187(\cdots)$. Orientation and scale as in Fig. la.

females to alternate roosting sites. The simultaneous departure of first year and adult females from a colony in the autumn and their subsequent return to the same colony the following spring also suggests that young of the year routinely follow adult females. An anecdotal observation confirms that adult females also follow other adult females. During the summer of 1988 we captured 10 pregnant females from each of two other colonies, Smith and Thompson (Wilkinson, in press), in order to study mother-infant communication (Scherrer 1991). The Smith colony was $10 \mathrm{~km}$ south and the Thompson colony over $50 \mathrm{~km}$ south of the captive location. After a week in captivity, several bats escaped. All of the Smith bats that escaped were subsequently recaptured at the Smith colony including one of the two Thompson bats that escaped. Because these bats migrate south, and as shown above, rarely forage more than $3 \mathrm{~km}$ from a colony, the Thompson bat escaped in an unfamiliar area and apparently followed one or more Smith bats to their colony.

\section{Information Parasitism or Exchange?}

Given that bats sometimes follow each other, does information parasitism or exchange occur? This distinction relates to which parties benefit by the interaction, not necessarily to any difference in communication. Information parasitism implies that two categories of individuals, leaders and 
followers, exist such that any information gained by a follower has either a negative effect or no effect on a leader. For example, the roost exclusion experiment could be explained by naive young bats parasitizing experienced adult bats by following them to hollow trees. Information exchange, on the other hand, implies an eventual mutual benefit and requires that an individual alternate between leading and following. Three lines of evidence indicate that following other bats to feeding sites represents a conditional strategy that depends on prior foraging success and eventually results in information exchange among nursery colony members.

The first line of evidence is that prey patches are sufficiently rich to promote sharing. The density of prey at a trapping site often exceeded the average prey density by a factor of two or more. Although we could not estimate the amount of prey in a patch, we routinely captured more small flies and beetles in $1 \mathrm{~h}$ at a trap than one bat could ingest on a single trip. Given that mass emergences often took place over entire ponds that were 1000 or more times the diameter of one suction trap, rich trapping sites could provide above average prey densities for more than one bat over several nights.

This conclusion rests on the assumption that the suction traps provide relative estimates of $N$. humeralis prey. Because bats sighted using bat detectors and spotlights typically hunted above the height of the suction traps, foraging bats might encounter different prey species and densities than the traps sampled. However, the presence of the same flies in trap samples and faecal pellets indicate that the traps captured at least some bat prey. Furthermore, the significant relationships between the number of foraging trips and both average prey density as well as the coefficient of variation in prey density also suggest that the suction traps sample variation in available bat prey. The negative relationship between average prey density and mass of returning bats implies that bats capture fewer insects per trip during periods of high prey density. Such a decrease in load size would be consistent with the marginal value theorem (Orians \& Pearson 1979 ) if prey become available closer to the colony as prey density increases, thereby allowing bats to spend less time foraging during each trip. Although our methods for estimating diet, by counting mandibles and legs to estimate numbers of insects in a faecal pellet, can be questioned because we assumed that different orders of insects would leave similar amounts of undigested parts, Fenton et al.
(1977) concluded that an African member of the genus, $N$. schlieffenii, also prefers small beetles and flies.

The foraging behaviour of $N$. humeralis is consistent with a prey distribution that is sufficiently clumped to permit patch sharing. The radio-tracking data show that two or more bats often foraged in the same area during a night. Although these spatial associations could result from bats independently locating rich food sites or habitat heterogeneity, bats foraged in all directions from the colony and three of the 12 radio-tagged bats exhibited coordinated flying with another bat on at least one night as expected if one bat followed the other. Furthermore, $15 \%$ of direct observations of foraging evening bats using spotlights and bat detectors involved two or more bats foraging simultaneously at one site.

The second line of evidence supporting information exchange is that above average prey density sites persist for no more than a few nights: long enough to allow sharing but short enough to prevent maintenance of territories from being profitable. Thus, the insect sampling data suggest that unsuccessful bats that follow successful bats on the same night or even on a subsequent night could encounter prey at above average levels. Because no site persisted with the highest prey density for more than a few days, every bat in a colony eventually had to seek alternate foraging sites to avoid foraging in a location with below-average prey densities.

The radio-tracking data are also consistent with this description of patch duration. Over half of all bats radio-tracked on successive nights returned to their previous foraging site, but the remainder initiated foraging in new sites. Bats also changed foraging locations within nights; sometimes travelling a kilometre or more in the opposite direction from previous foraging sites. Although I was unable to estimate mass from returning radio-tagged bats prior to a foraging location switch, I do know that $20 \%$ of foraging bats returned without gaining weight and, therefore, provided a pool of individuals that had to seek prey in new locations or follow previously successful foragers.

The third and most supportive line of evidence for information exchange comes from the video-taped records of departures, arrivals and weights. Following behaviour after the initial foraging trip occurred more often than expected by chance on numerous nights in both years of the study and involved both adult and juvenile bats. A majority of adult females at the Zion colony both departed before and after 
other bats in opposition to an interpretation of obligate information parasitism. Following bats were typically unsuccessful foragers that followed previously successful foragers. Because followers returned weighing $2 \cdot 2 \mathrm{~g}$ more than they had after their previous trip while unsuccessful bats which did not subsequently follow only gained $0.7 \mathrm{~g}$ on their next trip, following improves foraging success. Given that we did not observe any behaviour that might have facilitated the capture success of two bats foraging in the same area, such as herding or exposing cryptic prey, 1 infer that followers improved their foraging success by locating and exploiting rich prey patches.

\section{Passive or Active Information Transfer?}

Some discussions of information transfer (e.g. Ward \& Zahavi 1973; Waltz 1982; Brown et al. 1991) pose a third question that relates to the intention of the action, i.e. is information transfer passive or active? Passive information transfer occurs when one animal copies another, such as when a previously unsuccessful individual follows another to a feeding site. Active information transfer, on the other hand, involves an animal signalling semantic information about the environment to others and, therefore, requires some method for symbolizing the environment. The classic example of active information transfer among animals is the honey bee, Apis mellifera, dance (von Frisch 1967). Many social ants also signal food or nesting site location to other colony members but use chemical rather than auditory cues (Holldobler \& Wilson 1990). Chimpanzees, Pan troglodytes (Wrangham 1986), toque macaques, Macaca sinica (Dittus 1984), humpback whales, Megaptera novaeangliae (D'Vincent et al. 1985), osprey (Greene 1987) and ravens (Heinrich 1988) have been reported to vocalize when food is discovered, although in each case the vocalization is also used in other contexts. Recent playback studies by Brown et al. (1991) demonstrate that cliff swallows use a unique call to advertise foraging sites.

Passive information transfer has been documented for foraging Myotis lucifugus (Barclay 1982 ) by broadcasting feeding buzzes made by $M$. lucifugus and Eptesicus fuscus to simulate bats catching insects. Thus, other vespertilionid bats use echolocation calls to locate feeding patches currently being exploited. An individual $N$. humeralis that has not found prey may detect and subsequently follow a previously successful forager without much more difficulty. Bats that have recently eaten $2-4 \mathrm{~g}$ of insects are conspicuous when captured by their distended abdomens and their high rates of urination. Because $N$. humeralis usually roost in compact clusters of two to 10 bats within an attic, a simple rule, such as follow the echolocation calls of any departing neighbour that smells of fresh urine, would result in passive information transfer.

The vocalizations that we heard and recorded from excluded bats as they attempted to enter their attic roosts could represent active information transfer if those calls facilitate group departures by recruiting other bats. Although related evening bats exist within nursery colonies as a consequence of past natal philopatry, high juvenile mortality causes the average relatedness within a colony to be nearly zero (Wilkinson, in press). Thus, few if any bats that hear these calls are related to each other. An alternative interpretation for the calls is that they are alarm calls. Playback experiments are needed to elucidate the function of these vocalizations.

Although information transfer has been suggested as a possible benefit of communal roosting in frugivorous bats (Fleming 1982), neither fruit nor nectar are distributed unpredictably in space. By monitoring known food trees, animals can independently gather information that can be used to predict when those food sources will be available. For these reasons, information exchange about fruit or nectar sources, as has been suggested for Phyllostomus hastatus (McCracken \& Bradbury 1981) and Leptonycteris sanbornii (Howell 1979), seems less plausible than individual recruitment or some direct advantge of flock feeding. Truly unpredictable but rich foraging patches, such as may be exploited by fish-eating, blood-drinking, or insecteating bats, are more likely to permit information exchange and as a consequence, favour colonial breeding or communal roosting.

\section{ACKNOWLEDGMENTS}

I thank J. Grace, F. Mayer, D. O'Reilly, A. Scherrer, S. Steele and L. Wolfenbarger for help in the field, A. Chapman, K. Gaffke, P. Fauth, H. Fogel, R. Fundyga, R. Lauk, P. Lorch, C. Matthews and S. Robinson for assistance scoring videotapes, the Hutton, Easton, Busby and McClain families for 
access to bat colonies, and G. Borgia for loan of a camcorder. J. Balcombe, G. Borgia, P. Lorch, D. Winkler and an anonymous referee made helpful comments on the manuscript for which I am grateful. The University of Maryland Animal Care and Use Committee reviewed and approved the tissue sampling (protocol number R-87-40) and doublylabelled water (R-88-12) procedures. This work was supported by a Searle Scholar Award from the Chicago Community Trust and a biomedical research support grant from the University of Maryland.

\section{REFERENCES}

Alexander, R. D. 1974. The evolution of social behaviour. A. Rev. Ecol. Syst., 5, 325-383.

Barclay, R. M. R. 1982. Inter-individual use of echolocation calls: eavesdropping by bats. Behav. Ecol. Sociobiol., 10, 271-275.

Bayer, R. D. 1982. How important are bird colonies as information centers? $A u k, 99,31-40$.

Boyd, R. \& Richerson, P. J. 1985. The Evolution of Culture. Chicago: University of Chicago Press.

Boyd, R. \& Richerson, P. J. 1988. The evolution of reciprocity in sizable groups. J. theor. Biol., 132, 337-356.

Brown, C. R. 1984. Laying eggs in a neighbor's nest: benefit and cost of colonial nesting in swallows. Science, 224, 518-519.

Brown, C. R. 1986. Cliff swallow colonies as information centers. Science, 234, 83-85.

Brown, C. R. 1988a. Enhanced foraging efficiency through information centers: a benefit of coloniality in cliff swallows. Ecology, 69, 602-613.

Brown, C. R. 1988b. Social foraging in cliff swallows: local enhancement, risk sensitivity, competition and the avoidance of predators. Anim. Behav., 36, 780-792.

Brown, C. R. \& Brown, M. B. 1986. Ectoparasitism as a cost of coloniality in cliff swallows (Hirundo pyrrhonota). Ecology, 67, 1206-1218.

Brown, C. R. \& Brown, M. B. 1988. A new form of reproductive parasitism in cliff swallows. Nature, Lond., 331, 66-68.

Brown, C. R., Brown, M. B. \& Shaffer, M. L. 1991. Foodsharing signals among socially foraging cliff swallows. Anim. Behav., 42, 551-564.

Custer, T. W. \& Osborn, R. G. 1978. Feeding habitat use by colonially-breeding herons, egrets, and ibises in North Carolina. Auk, 95, 733-743.

Dittus, W.P. J. 1984. Toque macaque food calls: semantic communication concerning food distribution in the environment. Anim. Behav., 32, 470-477.

D'Vincent, C. G., Nilson, R. M. \& Hanna, R. E. 1985. Vocalization and coordinated feeding behavior of the humpback whale in southeastern Alaska. Sci. Rep. Whales Res. Inst., 36, 41-47.

Erwin, R. M. 1978. Coloniality in terns: the role of social feeding. Condor, 80, 211-215.
Fenton, M. B., Boyle, N. G. H., Harrison, T. M. \& Oxley, D. J. 1977. Activity patterns, habitat use and prey selection by some African insectivorous bats. Biotropica, 9 , 73-85.

Fleming, T. H. 1982. Foraging strategies of plant-visiting bats. In: Ecology of Bats (Ed. by T. H. Kunz), pp. 287-325. New York: Plenum Press.

von Frisch, K. 1967. The Dance Language and Orientation of Bees. Cambridge, Massachusetts: Harvard University Press.

Galef, B. C. 1991. Information centres of Norway rats: sites for information exchange and information parasitism. Anim. Behav., 41, 295-301.

Gotmark, F., Winkler, D. W. \& Andersson, M. 1986. Flock-feeding on fish schools increases individual success in gulls. Nature, Lond., 319, 589-591.

Greene, E. 1987. Individuals in an osprey colony discriminate between high and low quality information. Nature. Lond., 329, 239-241.

Heinrich, B. 1988. Food sharing in the raven, Corvus corax. In: The Ecology of Social Behavior (Ed. by C. N. Slobodchikoff), pp. 285-311. New York: Academic Press.

Holldobler, B. \& Wilson, E. O. 1990. The Ants. Cambridge, Massachusetts: Harvard University Press.

Hoogland, J. L. 1979. Aggression, ectoparasitism, and other possible costs of praire dog (Sciuridae, Cynomys spp.) coloniality. Behaviour, 69, 1-35.

Howell, D. J. 1979. Flock foraging in nectar-feeding bats: advantages to the bats and to the host plants. Am. Nat. $114,23-49$.

Humphrey, S. R. \& Cope, J. B. 1970. Population samples of the evening bat, Nycticeius humeralis. J. Mammal., $51,399-401$.

Jones, C. 1967. Growth, development, and wing loading in the evening bat, Nycticeius humeralis (Rafinesque). $J$. Mammal., 48, 1-19.

Kenward, R. E. 1978. Hawks and doves: factors affecting success and selection in goshawk attacks on woodpigeons. J. Anim. Ecol., 47, 449-460.

Krebs, J. R. 1974. Colonial nesting and social feeding as strategies for exploiting food resources in the great blue heron (Ardea herodias). Behaviour, 51, 99-134.

Loman, J. \& Tamm, S. 1980. Do roosts serve as 'information centres' for crows and ravens? Am. Nat.. 115, 285-289.

McCracken, G. F. \& Bradbury, J. W. 1981. Social organization and kinship in the polygynous bat Phyllostomus hastatus. Behav. Ecol. Sociobiol., 8, 11-34.

Mock D. W., Lamey, T. C. \& Thompson, D. B. A. 1988. Falsifiability and the information centre hypothesis. Ornis Scand., 19, 231-248.

Orians, G. H. \& Pearson, N. E. 1979. On the theory of central place foraging. In: Analysis of Ecological Systems (Ed. by D. J. Horn, R. D. Mitchell \& C. R. Stairs), pp. 154-177. Columbus: Ohio State University Press.

Rabenold, P. P. 1987. Recruitment to food in black vultures: evidence for following from communal roosts. Anim. Behav., 35, 1775-1785.

Richner, H. \& Marclay, C. 1991. Evolution of avian roosting behaviour: a test of the information centre hypothesis and of a critical assumption. Anim. Behav.. 41, 433-438. 
Scherrer, J. A. 1991. Variation and early ontogeny of isolation calls in evening bats, Nycticeius humeralis. M.S. thesis, University of Maryland, College Park.

Southwood, T. R. E. 1970. Ecological Methods. New York: Chapman \& Hall.

Steele, S. R. E. 1991. The energetics of reproduction in the evening bat, Nycticeius humeralis. M.S. thesis, University of Maryland, College Park.

Taylor, L. R. \& Palmer, J. M. P. 1972. Aerial sampling. In: Aphid Technology (Ed. by H. F. van Emden), pp. 189-234. New York: Academic Press.

Waltz, E. C. 1982. Resource characteristics and the evolution of information centers. Am. Nat., 119, 73-90.

Waltz, E. C. 1987. A test of the information-centre hypothesis in two colonies of common terns, Sterna hirundo. Anim. Behav., 35, 48-59.

Ward, P. 1965. Feeding ecology of the black-faced dioch Quelea quelea in Nigeria. Ibis, 107, 173-214.

Ward, P. \& Zahavi, A. 1973. The importance of certain assemblages of birds as 'information-centres' for foodfinding. Ibis, 115, 517-534.

Watkins, L. C. 1970. Observations on the distribution and natural history of the evening bat (Nycticeius humeralis) in northwestern Missouri and adjacent Iowa. Trans. Kans. Acad. Sci., 72, 330-336.
Watkins, L. C. \& Shump, K. A. 1981. Behaviour of the evening bat Nycticeius humeralis at a nursery roost. Am. Midl. Nat., 105, 258-268.

Weatherhead, P. J. 1987. Field tests of information transfer in communually roosting birds. Anim. Behav., 35, 614-615.

Wenzel, J. W. \& Pickering, J. 1991. Cooperative foraging, productivity, and the central limit theorem. Proc. natn. Acad. Sci., 88, 36-38.

Wilkinson, G. S. 1985. The social organization of the common vampire bat. I. Pattern and cause of association. Behav. Ecol. Sociobiol., 17, 111-121.

Wilkinson, G. S. In press. Communal nursing in the evening bat, Nycticeius humeralis. Behav. Ecol. Sociobiol.

Wilkinson, G. S. \& Bradbury, J. W. 1988. Radio telemetry: techniques and analysis. In: Ecological and Behavioral Methods for the Study of Bats (Ed. by T. H. Kunz), pp. 105-124. Washington, D.C.: Smithsonian Institution Press.

Wilkinson, G. S. \& Chapman, A. S. 1991, Length and sequence variation in evening bat d-loop mtDNA. Genetics, 128, 607-617.

Wrangham, R. W. 1986. Feeding behaviour of chimpanzees in Gombe National Park, Tanzania. In: Primate Ecology (Ed. by T. H. Clutton-Brock), pp. 503-538. London: Academic Press. 